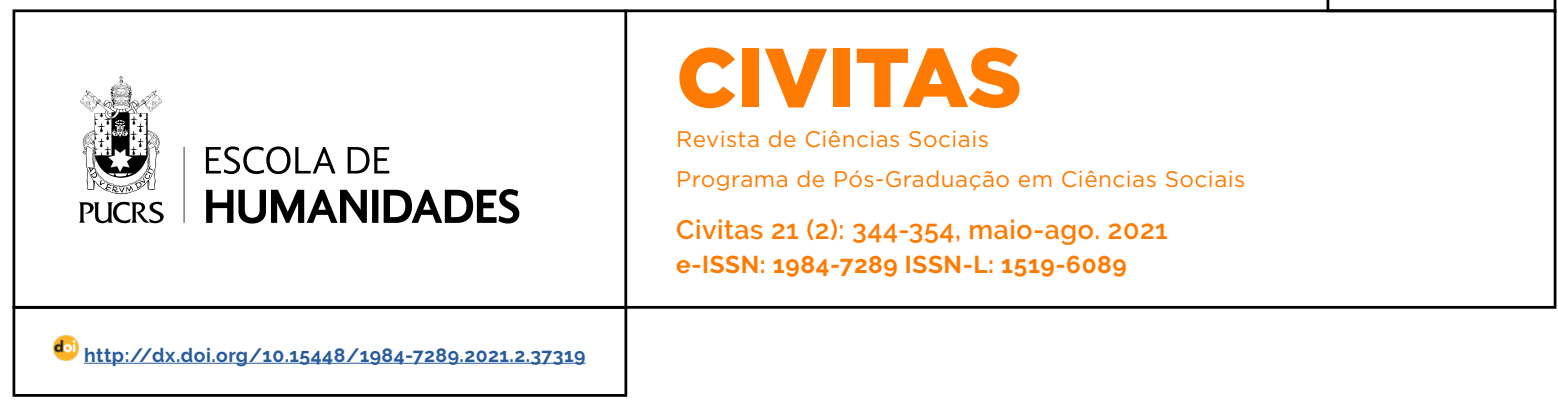

\title{
ARTIGOS/ARTICLES
}

\section{Condição juvenil, desigualdades de gênero e processos de exclusão nas aulas de educação física escolar}

\author{
Youth, gender inequalities and processes of exclusion in physical education school classes \\ Condición juvenil, desigualdad de género y procesos exclucion en las clases de \\ educación física en la escuela
}

\section{Tarcisio Augusto Alves da Silva ${ }^{1}$}

orcid.org/0000-0003-2956-3512 deescada@yahoo.com.br

Recebido: 9 mar. 2020 Aprovado: 7 dez. 2020 Publicado: 24 ago. 2021

\section{(c) (i)}

Artigo está licenciado sob forma de uma licença Creative Commons Atribuição 4.0 Internacional.
Resumo: Apresentamos neste texto os resultados de um estudo que revela as memórias de estudantes nas aulas de Educação Física escolar. Para isso, procuramos discutir como a condição juvenil das estudantes do ensino médio e as desigualdades de gênero afetam e conduzem meninas a um processo de exclusão nessas aulas. A investigação foi realizada por meio de entrevistas semiestruturadas com sessenta estudantes do $3 .^{\circ}$ ano do ensino médio, em seis escolas públicas e seis escolas privadas de Pernambuco. O estudo revela que as experiências das estudantes estão marcadas por um processo de desigualdade de gênero que encontra amparo na ausência da intervenção do(a) professor(a). Palavras-chave: Gênero. Desigualdade. Exclusão.

Abstract: This paper presents the results of a study on how students build memories in School's Physical Education classes. To this end, we seek to discuss how youth and gender inequalities in high school can affect teenage girls and influence them into excluding these classes. The investigation was carried out through semi-structured interviews with sixty 3rd year high school students, in six public schools and six private schools in Pernambuco. The study reveals that the students' experiences are marked by a process of gender inequality, which is strenghted by the absence of teacher's intervention.

Keywords: Gender. Inequality. Exclusion.

Resumen: En este artículo presentamos los resultados de un estudio a partir de relatos de estudiantes sobre clases de educación física en la escuela. Con este fin, buscamos discutir cómo la condición juvenil de los estudiantes de secundaria y las desigualdades de género afectan y llevan a las niñas a un proceso de exclusión en está clases. La investigación se llevó a cabo através de entrevistas semiestructuradas con sesenta estudiantes del tercer año de secundaria, en seis escuelas públicas y seis escuelas privadas en el estado de Pernambuco. El estudio revela que las experiencias de los estudiantes están marcadas por un proceso de desigualdad de género amparadas en la ausencia de intervención del maestro.

Palabras clave: Género. Desigualdad. Exclusión.

\section{Introdução}

A condição juvenil é um conceito desenvolvido dentro da Sociologia das Juventudes e diz respeito, entre outros aspectos, às representações e imagens estabelecidas socialmente sobre os jovens. Dela derivam interpretações de como a população jovem experimenta esse ciclo da vida, levando em conta sua vivência, seja a partir da classe social, da etnia, da 
cor da pele ou do gênero. Essas variáveis, por sua vez, permitem um enquadramento especifico e um entendimento plural das formas como as juventudes se colocam no mundo, considerando que as dimensões temporais e geográficas são mediações presentes na constituição da condição juvenil.

Para fins do presente trabalho, partimos do pressuposto de que existe uma convergência importante entre a condição juvenil e as desigualdades de gênero com consequências especíicas, sejam elas simbólicas, materiais, psicológicas, econômicas ou políticas, à vida das meninas em relação aos meninos. Desse modo, a condição juvenil para mulheres concentra, em cada período histórico e espaço geográfico, um conjunto de representações, imagens e valores compartilhados socialmente sobre o papel e o lugar das mulheres em cada sociedade.

Dito isso, as aulas de Educação Física podem se revelar como uma excelente oportunidade de superação das desigualdades de gênero e de exclusão que se materializam no ambiente escolar e na experiência de muitas estudantes. No entanto, uma rápida pesquisa em sites de busca tende a identificar uma larga literatura capaz de fundamentar essa evidência, mas, sobretudo, apontando a permanência de oportunidades diferenciadas entre meninos e meninas em vivências de práticas corporais na escola.

Ao resgatar essa discussão consideramos necessário investigar memórias entrelaçadas com a não participação das meninas nas aulas de Educação Física. Para tanto, realizamos um estudo em torno da seguinte questão: o que revelam as memórias e narrativas de meninas sobre as aulas de Educação Física?

O desenvolvimento da pesquisa contou a visita a doze escolas localizadas na região metropolitana do Recife, Pernambuco, sendo seis da rede pública (municipal ou estadual) e seis da rede privada de ensino, assim distribuídas: oito escolas no Recife, uma em Olinda, uma em Paulista, uma em Camaragibe e uma em São Lourenço da Mata.

Para a coleta dos dados, realizamos entrevistas estruturadas, compostas de quatro perguntas, aplicadas a um conjunto de sessenta estudantes, matriculadas no terceiro ano do ensino médio. A observação direta nos espaços das escolas e nas aulas de Educação Física foi um importante instrumento ao possibilitar a familiarização com os contextos escolares estudados. Às direções das escolas foi apresentado o Termo de Consentimento Livre e Esclarecido e encaminhado às familias, com o objetivo de garantir os aspectos éticos da pesquisa, sobretudo por estarmos investigando jovens adolescentes.

Por meio das entrevistas, resgatamos as memórias das estudantes em relação à sua participação e experiência nas aulas de Educação Física até o momento da coleta de dados. Com isso, procuramos entender o que explica o abandono, ou apatia, das estudantes nas aulas de Educação Física, considerando que havíamos identificado a presença desses elementos em licenciandas e futuras professoras da disciplina. Nosso interesse se debruça, portanto, na compreensão de quais aspectos interferem na participação, ou não participação, das estudantes no decorrer das aulas de Educação Física. Com o presente texto, objetivamos: (a) analisar o que revelam as experiências, as memórias e as narrativas das estudantes do terceiro ano do ensino médio nas aulas de Educação Física; (b) apresentar quais os sentidos atribuídos pelas estudantes às aulas de Educação Física; (c) indicar quais atividades mais excluem e incluem as meninas em suas experiências nessas aulas.

\section{A vivência da condição juvenil para as estudantes}

Em muitas sociedades, a condição juvenil é vivenciada pela inserção dos jovens em instituições situadas na segunda socialização, como a igreja, a escola e o mundo do trabalho. A função integradora desses agentes é reconhecida por seu papel de introduzir o individuo, já absorvido pelas regras sociais, a um universo mais amplo de sociabilidade, seja reforçando o sistema em que se encontra inserido ou apresentando novos elementos a ele.

A escola expressa uma dimensão da condição juvenil porque, dentre as muitas representações que se constroem socialmente sobre as juven- 
tudes, está aquela em que ela necessita preparar-se para a vida adulta, em um processo que ficou conhecido como moratória social. ${ }^{2}$ Ou seja:

pretensa condição da juventude no mundo moderno: separação relativa dos jovens do mundo adulto e público para o aprendizado de hábitos e valores básicos, que os predisponham a assumir papéis sociais requeridos pela sociedade quando se tornarem adultos (Groppo 2015, 12).

Entretanto, a máxima "o jovem precisa estar na escola" se coloca como uma grande preocupação quando pesquisas apontam o aumento quantitativo daqueles que "nem estudam nem trabalham". Com efeito, são as mulheres jovens as mais atingidas por esse fenômeno, pois precisam "realizar afazeres domésticos, cuidar de filho ou outros parentes" (IBGE 2019, 45) expressando um sistema de disposições incorporadas naquilo que Bourdieu (1996) definiu como habitus.

Esse fato reflete um aspecto da condição juvenil vivenciada, principalmente, por muitas jovens de classes pobres ou culturas em que o acesso à educação formal é pouco valorizado ou negado. Para Minayo (2011), o conceito de condição juvenil possui muitas acepções e uma delas enfatiza as desigualdades de classe, de gênero e de cor. Nesse sentido, "a condição juvenil é definida pelo fato de os indivíduos estarem vivendo um período específico do ciclo de vida, em um determinado momento histórico e em um peculiar cenário cultural" (Minayo 2011, 19).

Para Dayrell $(2007,1108)$ o conceito faz referência:

ao modo como uma sociedade constitui e atribui significado a esse momento do ciclo da vida, no contexto de uma dimensão histórico- geracional, mas também à sua situação, ou seja, o modo como tal condição é vivida a partir dos diversos recortes referidos às diferenças sociais - classe, gênero, etnia etc.

Desse modo, ao considerarmos a condição juvenil, a partir da vivência própria das mulheres, estamos nos reportando a um conjunto de representações, imagens e discursos construídos socialmente do que se esperar a respeito de como se formam e devem agir as jovens, sobretudo aquelas que conseguem acessar e permanecer dentro das instituições de ensino. Todavia, entendemos que a condição juvenil não se coloca como categoria estática e tampouco os sujeitos nela enquadrados se posicionam de forma passiva diante das regras e normas sociais estabelecidas como hegemônicas.

Ademais, embora a condição juvenil reflita as representações, as imagens e os discursos sobre os jovens, revelando, em parte, o que a sociedade espera e deseja deles, a situação juvenil diz respeito a como essa condição é vivida e pode ou não corresponder à forma como a juventude foi idealizada.

Portanto, parte dessa compreensão sugere que a condição juvenil se mostra em sua interseção com a noção de desigualdades de gênero como uma importante categoria que nos auxilia a pensar o lugar social ocupado pelas jovens estudantes do ensino médio nas aulas de Educação Física.

\section{Homens e mulheres: as relações desiguais de gênero}

Para se entender os processos que produzem assimetrias de poder, privilégios, discriminação e toda forma de desigualdade presentes na relação entre homens e mulheres, o termo gênero tem se mostrado, nos últimos tempos, uma importante categoria analítica ao permitir desnaturalizar situações e interpretações pautadas em pressupostos de determinação biológica dos papéis sociais dos indivíduos.

Utilizando a categoria gênero para analisar a prática da Educação Física escolar, é possível observar como lugares distintos são ocupados por meninos e meninas por meio da proposição de atividades estigmatizadoras. Essas tomam como base o senso comum ao atribuir aos primeiros, por sua condição física, um conjunto de habilidades corporais definidas biologicamente,

\footnotetext{
2 A noção de moratória social é bastante criticada, pois nem a todos os jovens é concebido o tempo de preparação para a vida adulta acessando instituições como a escola, uma vez que são introduzidos no mundo do trabalho antecipadamente. Ao mesmo tempo, essa ideia contribui para pensar a juventude apenas como uma etapa do ciclo de vida, e não como condição influenciada e influente das diferentes culturas nas quais se encontra inserida.
} 
colocado como fundamental ao desenvolvimento exitoso em muitas das linguagens dessa área de conhecimento, como os esportes ou lutas.

Esse fato reforça a dominação masculina expressa na divisão entre os sexos e que, para Bourdieu (2017), estaria na ordem das coisas, no estado objetivado, em estado incorporado e no funcionamento dos esquemas de percepção de pensamento e ação. Ademais, a diferença biológica entre os sexos, referenciada pela diferença anatômica entre órgãos sexuais, tem sido utilizada como justificativa natural da distinção socialmente construída entre os gêneros. Esse entendimento reverbera, por sua vez, na condição juvenil de como os sujeitos desse grupo populacional vivenciam sua juventude.

A evolução da legislação educacional brasileira revela em sua história um passado em que a diferença biológica e o escopo moral reforçavam a divisão entre os sexos, validando padrões sociais de comportamento pelos quais os corpos de meninos e meninas eram dispostos nos estabelecimentos escolares. Portanto,

a atual inexistência de legislações no Brasil que proponham a separação de meninos e meninas não significa que essa prática tenha sido completamente abolida das escolas. A separação ocorre e se justifica em nome de determinadas concepções das possibilidades do corpo diante do movimento, percebidas como distintas para homens e mulheres (Dornelles e Fraga 2009, 164).

A ocupação dos espaços (privado às mulheres e público aos homens), a posição social dos corpos, sua maneira de andar, como se vestir e como se comportar são questões distintivas dos sexos masculino e feminino.

Em um estudo realizado por Uchoga e Altmann (2016), as autoras discutem como a "condição feminina" caracterizada, em geral, pela inferioridade é reforçada muito cedo no seio familiar, com brincadeiras entre seus membros, e continuada na escola (mesmo não sendo explorada por muitos educadores e estudantes), reafirmando o papel das meninas como coadjuvantes na realização de atividades nas aulas práticas de Educação Física. A investigação demonstrou que as meninas assu- miam uma posição secundária (nas aulas de Educação Física) em todas as execuções praticadas e, quando se exigia um conhecimento novo, elas nem tentavam realizar; já os meninos davam seu melhor potencial, mesmo em atividades pouco corriqueiras para eles, como a ginástica rítmica.

Nota-se que o lugar assumido pelas estudantes revela, portanto, uma dimensão cotidiana em que o termo gênero se encontra situado, ou seja, uma categoria fixa e naturalizada de comportamentos e de papéis sociais assumidos por meio de predicados biológicos (sobretudo os genitais) e inatos. O contraste a essa perspectiva está postulado em um entendimento de que gênero é uma construção social e, portanto, se forma com base nos valores, normas e regras de uma dada cultura e sociedade.

Essa segunda perspectiva aponta para a provisoriedade temporal e social das relações entre homens e mulheres ao expor distintos postulados impostos como forma de controle dos corpos femininos e justificativas à posição de subalternidade das mulheres na sociedade. Questionam-se, desse modo, regras, normas e valores com os quais os papéis sociais são construidos.

Nesse sentido, as famílias e a escola são responsáveis pela "construção e/ou reprodução de conceitos equivocados, ou melhor, valores estereotipados acerca das questões de gênero" (Cruz e Palmeira 2009, 117). Apesar da importância dessas duas instituições para construção de determinados valores, a sua reprodução e perpetuação não está restrita ao espaço familiar, tampouco à escola, como adverte Bourdieu (2017), observando que, além deles, o próprio estado serve de elaboração e imposição de principios de dominação que se exercem no âmbito privado.

A Educação Física escolar, embora tenha passado por um processo de renovação teórica, registra em sua trajetória orientações higienistas e militaristas, com a esportivização das práticas escolares influindo, até o momento, em certa perspectiva pedagógica e didática com a qual suas aulas são praticadas. Sob a influência dessas experiências, o corpo feminino pode ser relegado, muitas vezes, à condição de fragilidade, reforçando as aulas de Educação Física como espaço de exclusão. 
As diferentes experiências de corporeidade entre rapazes e moças, delimitadas pelas regras sociais, impõem aos garotos a "liberdade" e às garotas "privação" e colocam-nas em desvantagem em aulas de Educação Física quando o referencial, por exemplo, for orientado por características militaristas.

Os aspectos biofisiológicos, psicológicos e sociais dessa experiência são analisados por Saraiva et al. (2005), demonstrando-se as consequências das aulas que separavam meninas e meninos. No que tange ao biofisiológico, as meninas são prejudicadas porque experimentam menos oportunidades de vivências corporais. Em relação ao psicológico, o estímulo à independência dos meninos reforça uma ideia de superioridade dos homens sobre as mulheres, restando a elas a aceitação de sua condição de fragilidade. Já do ponto de vista social, há uma ratificação da desigualdade de oportunidades promovida pelas assimetrias construidas nos campos anteriores.

Por outro lado, para Gaspari et al. (2003), as vantagens de utilização de turmas mistas sustentam-se, principalmente, nas possibilidades de se educar e aprender através das diferenças, desenvolvendo atitudes de respeito mútuo, solidariedade e cooperação entre os estudantes e promovendo o questionamento de preconceitos de gênero por meio da alteridade.

Já a naturalização das diferenças de gênero, em seu enfoque biologicista, é responsável por produzir desigualdades e hierarquias que impactam na vivência escolar dos estudantes. Sob essa perspectiva, a feminilidade é tratada como passiva e frágil, enquanto a masculinidade é ativa e forte (Dornelles 2011), seja fora dos muros da escola ou na própria aula de Educação Física. Resulta disso, a separação do esporte para meninas e meninos, ressaltada pelos critérios da fragilidade feminina, direcionando as mulheres para modalidades que exigem menos força e os homens para aquelas atividades representadas por virilidade e energia.

Os fundamentos da desigualdade de gênero nada têm a ver com diferenças de gênero, uma vez que a primeira tende a promover a exclusão invocando critérios de distinção hierárquicas, en- quanto a segunda reivindica a identidade como uma forma de estar e se colocar no mundo. $O$ esforço, portanto, é, como nos lembra Bourdieu (2017), compreender como ocorre a des-historicização e a eternização das estruturas da divisão sexual para que as mulheres possam alcançar seu papel de agentes históricos.

Como se vê, o elemento da desigualdade de gênero é um aspecto recorrente em muitos relatos de pesquisa na área de Educação Física e se coloca como uma dimensão quase estrutural da vivência da condição juvenil para muitas mulheres.

\section{Futebol e futsal na escola e a reprodução de uma hexis corporal}

Considerando os esportes coletivos como uma das práticas de ensino da Educação Física escolar, é possível observar o protagonismo de um tipo específico de esporte sendo referenciado nas aulas, influenciado pela máxima de que o Brasil é o país do futebol. Não bastasse esse fato, é notório o quanto o futebol se caracteriza como uma prática esportiva dominada por homens, mesmo levando em conta uma pequena visibilidade recebida nos últimos tempos, com a formação de times e campeonatos, mesmo com baixos patrocínios, cujos sujeitos são mulheres.

No ambiente escolar, essa prática esportiva traz consigo várias possibilidades de aplicação pedagógica para interação entre meninos e meninas. Porém,

ainda que várias escolas e professores(as) venham trabalhando em regime de co-educação, a Educação Fisica parece ser a área onde as resistências ao trabalho integrado persistem [...] (Louro 2007, 72).

Deslocadas de experiências integradoras, as práticas educativas como o futebol e o futsal reproduzem na escola as assimetrias muito presentes na experiência do futebol profissional. 0 efeito imediato desse fenômeno estaria no ato educativo do corpo que pode ser explicado por uma experiência prática que engendra os esquemas fundamentais de incorporação do universo social com suas regras e valores (Bourdieu 2014), produzindo uma hexis corporal especifica. 
Como conceito, a hexis corporal revela o sentido do habitus incorporado, uma vez que ela se encontra "composta de um capital físico ou corporal, correspondente a uma disposição e a uma trajetória individual, mas também de uma dimensão coletivizada, de grupo" (Montagner 2006, 517).

Nesse sentido, a maioria das experiências com a prática de futebol e futsal na escola reforçam as premissas de que as diferenças entre os sexos são fundamentalmente biológicas e não culturais. Orientadas por essa premissa, o corpo é construido na lógica da divisão social e sexual do trabalho dando a ele uma fisionomia propriamente social (Bourdieu 2014).

Furlan e Santos (2008) apresentam as muitas barreiras do sexismo à prática do futebol na escola pelas meninas, destacadamente aquelas as quais associam sua imagem à homossexualidade ou os perigos de choque nos órgãos de função reprodutiva, além da ideia muito disseminada de ser um esporte para homens e não para mulheres. Essa constatação tende a demonstrar como o domínio masculino se impõe como ordem social e limitação à produção de outra hexis corporal onde as meninas possam se autoidentificar pela autonomia de seus corpos.

\section{Educação Física escolar: a experiência das estudantes}

Distintos significados associados à relevância da disciplina na trajetória das alunas foram verificados nos dados coletados, apontando para um reconhecimento da disciplina pela promoção da saúde e do cuidado com o corpo. Mesmo com algumas estudantes reconhecendo a importância da Educação Física para esse fim, destacou-se também a sua representação enquanto uma forma de distração e distensionamento. Os relatos a seguir procuram ilustrar essas observações:

Entrevistada A: [...] a importância das atividades físicas para a saúde corporal e em alguns casos mental.

Entrevistada B: É importante para promoção da saúde [...].

Entrevistada C: Importante para exercitar o corpo e uma forma de relaxar das outras matérias.
Entrevistada D: É bom para sair da sala, quebra a rotina, e é bom para estimular a prática de exercícios.

Da análise desses relatos, dois aspectos se destacam: a Educação Física como "promotora da saúde e da distração". Aqui é preciso refletir se a função ou a importância da Educação Física escolar seria a promoção da saúde. O efeito imediato desse aforismo impõe como conteúdo da Educação Física a saúde a ser alcançada por meio de exercicios físicos, esportes etc. Sua prática, portanto, permitiria o desenvolvimento saudável e a melhoria da qualidade de vida do sujeito.

O problema de fundo dessa compreensão está, do ponto de vista pedagógico, em seu fundamento positivista e na perspectiva do individualismo biológico por meio dos quais o conhecimento e a prática pedagógica se desenvolvem. Desloca-se, assim, o foco do processo de ensino-aprendizagem para a realização de práticas pouco reflexivas e torna-se a Educação Fisica a única responsável pela temática da saúde na escola. Ferreira $(2001,46)$ destaca que: "a vinculação exclusiva da prática do exercício à idéia [sic] de aptidão física permanente [...] não se mostra suficiente para sua relação de compromisso com a saúde". O autor defende que a saúde não é adquirida por mudanças de comportamento individual, porque variáveis sociopolítico-econômicas do problema transferem parte da responsabilidade do individuo por sua situação de vida para o conjunto da sociedade.

No que diz respeito ao entendimento da Educação Física como distração, segundo aspecto destacado da experiência das estudantes, Daólio (2005, 218) observa que as muitas críticas feitas à disciplina apontavam ser ela "vazia de conteúdo, por não possuir especificidade pedagógica, por ainda caracterizar-se pelo tecnicismo, ou mesmo ser encarada como mera recreação".

No quesito das diferenças de gênero entre meninos e meninas veremos que elas se convertem em desigualdades de gênero quando as estudantes não têm a possibilidade de realizar determinadas atividades, ou mesmo quando a ação pedagógica não proporciona a inclusão e 
o jogo misto. Nesse sentido, o fenômeno é bastante corriqueiro nas aulas práticas da disciplina em que, geralmente, os meninos praticam futsal e as meninas, vôlei. Nas ocasiões que ocorriam alguma atividade integradora, as estudantes destacaram a falta de respeito e a insensibilidade dos meninos para com elas. Ao mesmo tempo, evidenciaram como as diferenças entre os sexos eram exploradas de maneira hierarquizada, alimentando nas alunas o desinteresse pelas aulas, quando não eram excluidas ou escanteadas pela ausência de alternativas, que deveriam ser apresentadas pelo professor.

Ainda que o futsal e o futebol tenham sido citados como as atividades mais corriqueiras de integração entre meninos e meninas, as estudantes relataram que acabavam sendo excluidas das atividades coletivas, pois, na divisão de times, os meninos não as selecionavam para os jogos.

Estranhamente, nos diferentes contextos escolares estudados, o papel do professor figurou, com raras exceções, com uma postura de distanciamento quando as desigualdades de gêneros, inscritas nas relações sociais entre meninos e meninas, se manifestavam em suas aulas. Na maioria dos relatos, os professores são apresentados em uma posição de passividade diante da problemática. Em outros, os docentes são apontados reafirmando as diferenças de gênero ou invisibilizando-as nas propostas didáticas de suas aulas.

Foram raras as experiências em que houve menção a professores realizando a mediação dessas diferenças, interferindo e incluindo as estudantes nas práticas ou, ainda, dividindo o espaço de forma a promover a sua participação. Parte desse entendimento está presente nos estratos das entrevistas que selecionamos abaixo:

Entrevistada E: No Ensino Fundamental, principalmente, eu sofri muito preconceito porque sempre gostei de jogar futebol ou futsal e os professores não deixavam.

Entrevistada F: existiam diferenças nas práticas de futsal devido ao excesso de força dos meninos. As diferenças eram tratadas dividindo meninas só para jogar com meninas.

Entrevistada G: O professor separa o horário para os meninos e meninas para cada esporte.
Entrevistada H: Existe diferença pelos meninos não respeitarem as meninas, não medindo suas forças para jogar com as meninas. As diferenças poderiam ser tratadas por uma conversa entre o professor e os meninos.

Entrevistada I: Os meninos jogavam futebol e as meninas jogavam vôlei, pois os meninos não deixavam as meninas jogarem. A professora aceita isso e não se opõe, quando era para partir dela alguma atitude para isto não acontecer.

Entrevistada J: quando o assunto era futsal, os meninos jogavam, enquanto as meninas faziam relatório ou uma prática que não tinha a ver com o tema.

Como se vê, diferenças biológicas, estereótipos e várias nuances entre meninos e meninas se colocam na ordem do dia das relações construidas em muitas práticas de Educação Física escolar dos contextos investigados. Ao negligenciar seu olhar diante desse quadro, muitos docentes reproduzem e reforçam uma hierarquia e ideário em que a mulher é representada como inferior, frágil e pouco apta às atividades e esforços físicos. Apoia-se, desse modo, a lógica da dominação masculina (Bourdieu 2017) abrigada nas práticas pedagógicas nas aulas de Educação Física.

Bem observado por Bourdieu (2017, 22), ao referir-se à força da ordem masculina, "a visão de mundo androcêntrica impõe-se como neutra e não tem necessidade de enunciar em discursos que visem a legitimá-la", sua prática simplesmente é imposta.

Ao avançar para conhecer qual memória das aulas de Educação Física mais marcou a trajetória das estudantes, indagamos: haveria, em sua história escolar como mulher, algum fato a se destacar? Da análise realizada sobre os resultados das entrevistadas, destacamos, como reflexão, o quanto os processos de aprisionamento das pessoas a papéis sexuais e regras fixas de comportamento a eles associadas tendem a orientar determinadas relações sociais e pedagógicas, dentro da escola, que reforçam dimensões da dominação masculina sobre as estudantes, ao restringir e limitar suas possibilidades de formação e desenvolvimento humano.

Para ilustrar essa afirmativa, a entrevistada $Q$ declara: "Muita coisa era ensinada como esporte 
de menino e esporte de menina". Sua revelação é uma das mais expressivas observações e se alinha àquilo que Bourdieu (2017) considerava como divisão arbitrária entre homens e mulheres e que serve para eternizar o arbitrário cultural da dominação androcêntrica por meio das aulas de Educação Física.

Como elemento intensificador dessa situação, muitas alunas destacaram como a memória mais marcante o não posicionamento dos professores diante do preconceito em relação às meninas que gostavam e desejavam jogar futsal ou futebol. Portanto, o preconceito que sofreram aparece, no processo de pesquisa, como uma dimensão expressiva da desigualdade de gênero, conforme os fragmentos das entrevistas explicitam:

Entrevistada A: O fato de os professores não tomarem atitude em relação aos meninos não deixarem as meninas jogarem futsal. O preconceito por ser uma mulher que gosta de futsal.

Entrevistada D: os meninos sempre deixam as meninas meio que de lado quando tem aulas de futebol.

Entrevistada F: O que marcou negativamente é que os meninos chutavam muito forte.

Entrevistada $\mathrm{H}$ : As memórias que mais marcaram foram no Fundamental, onde tinha dias só para os meninos e dias só para meninas, porém só os meninos jogavam pela falta de meninas interessadas para jogar.

Entrevistada L: O professor não ligava se participávamos das aulas.

Entrevistada M: Minhas aulas de Educação Física não eram no horário normal e meu antigo professor não explicava as regras.

Por outro lado, as memórias das estudantes revelam lembranças também positivas quando se referem a aulas "diferenciadas", como dança e ginástica, embora permanecessem o preconceito e a resistência por parte dos meninos para realização dessas atividades, ancorando ainda mais a ideia de práticas distintas para meninas e meninos. Outras estudantes destacaram que, no ensino médio, além de terem a primeira professora de Educação Física, essa se mostrou preocupada com o aprendizado e enfatizava a participação de todos nas aulas. Os trechos das entrevistas abaixo procuram ilustrar parte desse entendimento:
Entrevistada N: a aula de ginástica rítmica e olimpica foi uma aula bem diferente. Eu gostei muito.

Entrevistada O: uma aula de dança que tivemos que fazer um trabalho e foi bem legal.

Entrevistada E: Algumas das boas memórias que tenho são do Ensino Médio, pois foi quando mudamos de professor e a nova professora nos incentivava a jogar o que a gente queria. O preconceito [era] por parte do professor [anterior], enquanto ele que deveria praticar a igualdade.

Entrevistada P: Em todas as escolas que passei sempre foram professores homens, nesta atual foi a única que uma mulher ministra a aula.

As memórias positivas e negativas delinearam as entrevistas de muitas alunas, embora o peso das experiências restritivas de sua corporeidade no papel de estudantes em aulas de Educação Fisica tenha sido a dimensão mais frequente dessas lembranças.

Mesmo várias estudantes relatando o prazer de haver vivenciado muitas modalidades esportivas e gostar delas, outras destacaram o trauma de se machucar pela força e competitividade com que meninos atuavam nas atividades. Além disso, foi muito comum encontrar em suas falas o registro da sensação de desconforto gerado pelos olhares e assédio dos meninos em atividades como futsal e vôlei, por conta das roupas utilizadas pelas meninas nessas modalidades.

Das aulas de Educação Física no ensino fundamental, uma das entrevistadas apresentou um dos relatos mais traumáticos. Segundo ela, sua condição corporal, fazendo referência ao fato de ser gorda, era explorada pelo professor do $8 .^{\circ}$ ano para reforçar a ideia de que não conseguiria realizar as atividades. $\mathrm{Na}$ entrevista, durante muitos momentos, foi necessário efetuar diversas pausas para que pudesse se recompor de uma memória tão triste. Por nunca ter denunciado aquela atitude, com vergonha de se expor, o professor não foi punido.

Por fim, a última questão apresentada às entrevistadas buscou identificar em qual temática ou conteúdo das aulas de Educação Física houve maior aprendizagem. Dos dados coletados, a maior recorrência dos conteúdos relacionados 
aos esportes, como vôlei, handebol, futsal e atletismo, mostra uma variedade de respostas associadas a essa questão. A ginástica e a dança são outros temas que, mesmo de maneira pouco expressiva, aparecem nos relatos. Ademais, em duas escolas, as estudantes destacaram que as aulas de Educação Física eram pouco planejadas e seus professores não demonstravam preocupação em discutir os conteúdos. Elas afirmaram que "se assustaram" ao chegar ao ensino médio, pois a professora assumiu outra postura. Os trechos abaixo comprovam a recorrência do conteúdo do esporte nas experiências das estudantes:

Entrevistada M: O vôlei foi um dos esportes que mais me interessei, mas o professor não explicava as normas e regras.

Entrevistada Q: [...] as aulas sempre eram voltadas para o esporte.

Entrevistada R: O professor ensinou as regras do vôlei e de outros esportes.

Analisadas as possibilidades de atividade de integração de meninos e meninas nas aulas de Educação Física, as referências aos esportes, a exemplo do vôlei e handebol, poderiam ser encaradas como possibilidades de inclusão das estudantes nessas aulas. No entanto, ao se privilegiar os conteúdos de esporte em detrimento das demais linguagens (o jogo, a dança, a ginástica e a luta), verifica-se o caráter de esportivização orientando forma e conteúdo dessa disciplina e dificultando uma maior possibilidade de integração que permitiria estabelecer estratégias de redução das desigualdades de gênero aqui já explicitadas.

\section{Considerações finais}

Atualmente, embora os ideais difundidos pelo feminismo, fundados na perspectiva da igualdade entre homens e mulheres, tendam a se popularizar, é possível, com a análise das práticas e atividades realizadas no âmbito da Educação Física escolar, entender parte do abandono, ou apatia, das estudantes nessas aulas motivadas por processos de desigualdades de gênero.

A condição juvenil em que as estudantes vivenciam sua juventude traduz parte de um ideal ou visão estigmatizada sobre as possibilidades de desenvolvimento dessas jovens, nesse caso, limitado à sua condição de mulher. O elemento limitador se personifica nos discursos e práticas verificados na proposição de aulas de Educação Física com uma distinção entre esporte de rapazes e moças.

Apesar de existir um discurso associado ao abandono, ou à apatia, nas aulas de Educação Física e aos aspectos de valorização moral da imagem dos corpos femininos, apontando para uma preocupação com a beleza e, desse modo, a recusa da participação nas atividades justificadas pelo incômodo causado pelo suor, a explicação da não participação das estudantes nas aulas deve ser buscada, também, na permanente desigualdade de gênero e de perpetuação de imagens preconcebidas de todo tipo em relação às meninas. Reforça-se, com isso, a condição juvenil vivenciada na experiência das jovens estudantes recortada por atributos que envolvem a ideia de feminilidade e de fragilidade e pela permanência de modelos de comportamento associados à condição de passividade das mulheres.

Tem-se, com isso, a produção de todo um aforismo levado em conta para excluir as mulheres de oportunidades que permitem o seu desenvolvimento humano, suas capacidades físicas, cognitivas e sociais. Dessa forma, os aspectos da problemática relacionada ao gênero que mais interferiram na participação das estudantes, no decorrer das aulas, foram os preconceitos atribuídos à sua condição biológica, à incapacidade dos meninos de realizar atividades físicas coletivas com elas e a não intervenção dos professores nas situações de discriminação para inclusão e integração das estudantes nas aulas.

Mesmo as memórias das aulas de Educação Física se apresentando com muitas experiências negativas, como a falta de respeito dos meninos, algumas poucas estudantes destacaram iniciativas pela busca de espaço nas aulas incentivando a formação de times de futebol feminino, apesar de serem rejeitadas tanto por professores quanto por alunos.

Por outro lado, as memórias das estudantes trazem à tona as práticas pedagógicas que de- 
monstram formas pouco dialógicas no processo de ensinar e, salvo exceção, reforçam o imaginário de dominação masculina e o principio de desigualdade entre os gêneros. Esse fato se coloca como um dos grandes desafios a serem transformados e se impõe como urgente no debate e na formação dos(as) futuros(as) professores(as) de Educação Física.

Ratificamos, com isso, a necessária formação de professores e professoras sensivel e adequada a auxiliar a superação das desigualdades de gênero, ressaltando os potenciais que as diferenças de gênero podem contribuir para a escola como um espaço de diversidades.

\section{Referências}

Bourdieu, Pierre. 2017. A dominação masculina. A condição feminina e a violência simbólica. 5. ed. Rio de Janeiro: BestBolso.

Bourdieu, Pierre. 1996. Razões práticas: sobre a teoria da ação. Campinas: Papirus.

Bourdieu, Pierre. 2014. Notas provisórias sobre a percepção social do corpo. Pro-Posições 25 (1): 247-256. https://doi.org/10.1590/S0103-072014000100014.

Cruz, Marlon Messias Santana e Fernanda Caroline Cerqueira Palmeira. 2009. Construção de identidade de gênero na Educação Física Escolar. Motriz: Revista de Educação Física 15 (1): 116-131.

Daólio, Jocimar. 2005. A educação física como prática cultural: tensões e riscos. Pensar a Prática 8 (2): 215-226. https://doi.org/10.5216/rpp.v8i2.115

Dayrell, Juarez. 2007. A escola "faz" as juventudes? Reflexões em torno da socialização juvenil. Educação \& Sociedade 28 (100): 1105-1128. https://dx.doi. org/10.1590/S0101-73302007000300022.

Dornelles, Priscila Gomes e Alex Branco Fraga. 2009. Aula mista versus aula separada? Uma questão de gênero recorrente na educação física escolar. Revista Brasileira de Docência, Ensino e Pesquisa em educação Fisica 1 (1): 141-156.

Dornelles, Priscila Gomes. 2011. Marcas de gênero na educação física escolar: a separação de meninos e meninas em foco. Motrivivência 23 (37): 12-29. https:// doi.org/10.5007/2175-8042.2011v23n37p12.

Ferreira, Marcos Santos. 2001. Aptidão física e saúde na educação física escolar: ampliando o enfoque. Revista Brasileira de Ciências do Esporte 22 (2): 41-54.

Furlan, Cássia Cristina e Patrícia Lessa dos Santos. 2008. Futebol Feminino e as barreiras do sexismo nas escolas: reflexões acerca da invisibilidade. Motrivivencia 20 (30): 28-43. https://doi.org/10.5007/2175-8042.2008n30p28
Gaspari, Telma Cristiane, Aline Di Thommazo, Valéria Battistuzzi Maciel et al. 2003. Possibilidades da Educação Física na escola: ouvindo os professores. Anais do VII EnFEFE. Niterói: Universidade federal Fluminense.

Groppo, Luís Antonio. 2015. Teorias críticas da juventude: geração, moratória social e subculturasjuvenis. Em Tese 12 (1): 4-33. https://doi.org/10.5007/1806-5023.2015V12n1p4.

IBGE (Instituto Brasileiro de Geografia e Estatistica). 2019. Sintese de indicadores sociais: uma análise das condições de vida da população brasileira. Coordenação de população e indicadores sociais. Rio de Janeiro: IBGE.

Louro, Guacira Lopes. 2007. Gênero, sexualidade e educação: uma perspectiva pós- estruturalista. 9. ed. Petrópolis: Vozes.

Minayo, Maria Cecília S. 2011. A condição juvenil no século XXI. In Amor e violência: um paradoxo das relações de namoro e do 'ficar' entre jovens brasileiros, organizado por Maria Cecilia Souza Minayo, Simone Gonçalves de Assis e Katie Njaine, 17-43. Rio de Janeiro: Editora Fiocruz. http://books.scielo.org.

Montagner, Miguel Ângelo. 2006. Pierre Bourdieu, o corpo e a saúde: algumas possibilidades teóricas. Ciência \& Saúde Coletiva 11 (2): 515-526. https://doi. org/10.1590/S1413-81232006000200028.

Saraiva, Maria do Carmo, Luciana Fiamoncini, Elisa Abrão e Ana Alonso Krischke. 2005. Ensinar e aprender em dança: evocando as "relações" em uma experiência contemporânea. In Práticas Corporais, vol. 2, organizado por Ana Márcia Silva e lara Regina Damiani, 61-78. Florianópolis: Nauemblu Ciência e Arte.

Uchoga, Liane Aparecida Roveran e Helena Altmann 2016. Educação física escolar e relações de gênero: diferentes modos de participar e arriscar-se nos conteúdos de aula. Revista Brasileira de Ciências do Esporte 38 (2): 163-170. https://doi.org/10.1016/j.rbce.2015.11.006.

\section{Agradecimentos}

O autor agradece aos estudantes da disciplina Sociologia das Práticas Corporais 2018.1, do curso de Licenciatura em Educação Física, da Universidade Federal Rural de Pernambuco, que participaram da coleta de dados da pesquisa: Luan Filipe, Danilo Araújo, Blenda Maria, Filipe André, Hugo Victor Endrios Santana, Catarina Gusmão, Raphael Montarroyos, Vinicius Alves, Marcos Emmanuel, Dennys Alisson, Elijacy Conceição, Girlaine Lourencio, Felipe Alves, João Crisson, Ronald de Oliveira, Danyella Karen, Fernanda Vitor, Matheus Henrique, Valeska Alves, Kleber Ferreira, Rhayana Gomes, Cirlene Araújo, Jessyca Adelino, Solane Vaz, Marcos Aureliano, Arthur Henrique, Helio rodrigues, Gean Carlos, Ibson Filipe. 


\section{Tarcísio Augusto Alves da Silva}

Doutor em Sociologia pela Universidade Federal de Pernambuco (UFPE), Recife, PE, Brasil; mestre em Serviço Social pela mesma instituição; professor da Universidade Federal Rural de Pernambuco (UFRP), Recife, PE, Brasil.

Os textos deste artigo foram revisados pela Poá Comunicação e submetidos para validação do autor antes da publicação. 